\title{
Non-conventional Band-notched UWB Antenna Design Based on Genetic Algorithm
}

\author{
Khelil Fertas, Soufiane Tebache, Fouad Fertas, and Rabia Aksas
}

\begin{abstract}
In this paper, an improved applied approach based on Genetic Algorithm (GA) for antenna design is presented. It is basically useful to overcome electromagnetic interferences in UWB applications. First, an antenna in the range 2.8 - $20 \mathrm{GHz}$ including UWB band was designed by using GA, then the undesired WiMAX band (3.5-3.8GHz) is rejected by optimizing appropriate Defected Ground Structure (DGS) filter. The proposed non-conventional filter consists of a matrix of rectangular cell shapes where each one is allocated by presence or absence of metal. The process is implemented in CST software using visual basic script. The method overcomes difficulties of conventional design. Furthermore, the optimized shape can be automatically obtained without appealing expert designers. Simulated and measured results demonstrate the effectiveness of the proposed design approach.
\end{abstract}

Keywords_-Ultra Wide Band (UWB), Genetic Algorithm (GA), Non conventional DGS filter.

\section{NOMENCLATURE}

$\begin{array}{ll}\text { GAO } & \text { Genetic Algorithm Optimisation. } \\ \text { UWB } & \text { Ultra Wide-Band. } \\ \text { DGS } & \text { Defected Ground Structure. } \\ \text { VBS } & \text { Visual Basic Script. } \\ \text { CST } & \text { Computer Simulation Technology. }\end{array}$

\section{INTRODUCTION}

Ultra Wide Band (UWB) antennas have been of great interest in nowadays telecommunications systems. However, extensive usage of UWB technology provides remarkable high level of interferences between users. Hence, reducing interferences requires a special treatment which can be achieved by incorporating band-reject filters in UWB antenna systems [1-4].

Filter optimization performance becomes very challenging as long as it should satisfy various aspects such as high rejection level in single or multi-band configurations, accuracy and ease of integration in small devices. Consequently, various methods were investigated to overcome this challenge [5-7]. In [5], traditional DGS technique is used in filter design. Authors in [6] proposed a Tri-stopband filter using metamaterial cells.

It is worthwhile to point out that conventional methods based on adding resonators or etching slots are almost time- consuming, complex and hardly achieve desired requirements. To surmount the disadvantage of using such techniques, a genetic algorithm optimization (GAO) has been widely exploited in the microwave and antenna applications [8-11].

GAO is an automatic method based on genetic concept. It is

Manuscript received April 19, 2021;revised June 14, 2021.

Khelil Fertas, Soufiane Tebache, Rabia Aksas are with the Electronics Department, Ecole Nationale Polytechnique, Algiers, ALGERIA. (e-mail: khelil.fertas@g.enp.edu.dz, soufiane.tebache@g.enp.edu.dz, rabia.aksas@g.enp.edu.dz).

Fouad Fertas is with the Electrical Engineering Department, University of Boumerdes, ALGERIA. (e-mail: f.fertas@univboumerdes.dz)

Digital Object Identifier (DOI): 10.53907/enpesj.v1i1.26 commonly used to solve optimization and search problems by exploiting some biologically inspired operators known as mutation, crossover and selection.

In this paper, a novel non-conventional defected ground structure (DGS) filter is proposed. It is designed for WiMAX (3.5$3.8 \mathrm{GHz}$ ) band rejection in wide-band antenna. The filter is optimized by GA method where the initial code is developed using visual basic script (VBS) which is integrated into CST environment for electromagnetic simulations.

\section{Antenna Configuration}

The optimized antenna with non-conventional DGS filter is depicted in Fig. 1. It consists of two sides over a Teflon substrate with relative permittivity $\varepsilon_{r}=2.4$ and height $h=1.6 \mathrm{~mm}$. The monopole antenna operating in the frequency band $2.8-20 \mathrm{GHz}$ is illustrated in Fig. 1(a). It is designed using the code developed in [12], which is based on genetic algorithm optimization and implemented on CST Microwave studio as a simulation tool. The $50 \Omega$ microstrip line is used to supply the antenna.

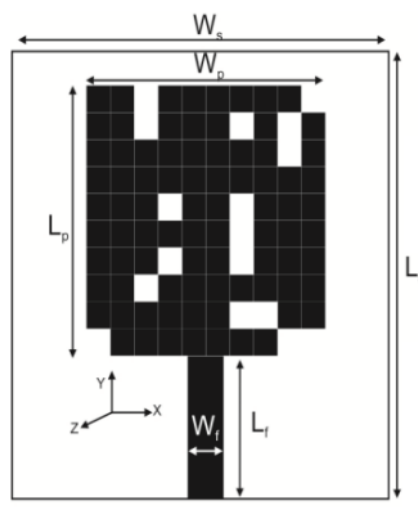

(a)

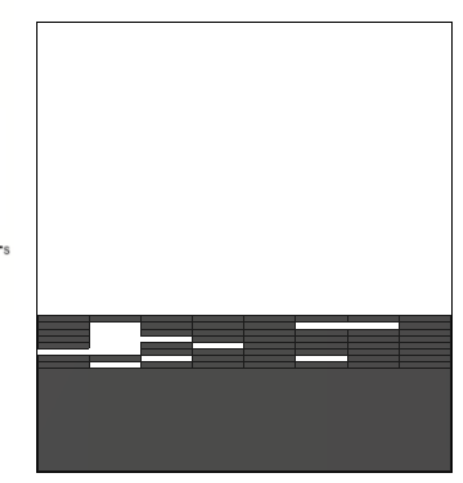

(b)
Fig. 1: Proposed antenna with non-conventional DGS filter. (a) Front view. (b) Back view. ( $L_{f}=18 \mathrm{~mm}, W_{f}=$ $3.1 \mathrm{~mm}, W_{s}=33 \mathrm{~mm}, L_{s}=43 \mathrm{~mm}, W_{p}=20 \mathrm{~mm}, L_{p}=$ $20 \mathrm{~mm}$ ).

Further, the effectiveness of the method is studied and extended in order to reject some intentionally undesired frequency- 
bands in the UWB. The process consists of optimizing a nonconventional DGS filter as seen in Fig. 1(b). The filter is made of a matrix of rectangular cell shapes where each one is allocated by presence or absence (slots) of metal, which are translated to binary code " 1 " and " 0 ", respectively. The dimension of each rectangle is set to $0.5 \times 4 \mathrm{~mm}^{2}$.

In order to find the best configuration, the GAO changes the pixel position in the area of DGS filter (situated at high current distribution location). Consequently, the current distribution is also modified according to the pixel distribution for suppressing undesired bands.

The code developed, based on different steps, is applied with optimization fitness value of multi-objective function, to achieve good rejection (good impedance mismatch) of $S_{11}$ in frequency band $[3.5-3.8 \mathrm{GHz}]$ that correspond to WiMAX standard. The first step consists to generating a random population of matrices corresponding to different shapes of the design where pixels are coded (either 1 or 0 value for presence/absence of the conductor respectively). In the second step, the generated populations are simulated so that the reflexion coefficient should satisfy the filter condition around the desired band. Then, the next generation is formed from the previous one with changes in pixel position in the area of DGS filter. This process is iteratively repeated until the satisfaction of the stop criterion (cost function) corresponding to the optimal solution.

The cost function of multi-objective problem is applied to attain good matching of the reflection coefficient $\left(\left|S_{11}\right|<-10 \mathrm{~dB}\right)$ in the desired bands $(3-3.5 \mathrm{GHz} \& 3.8-20 \mathrm{GHz})$ and impedance mismatch $\left(\left|S_{11}\right|>-10 d B\right)$ in the rejected WiMAX frequency band $(3.5-3.8 \mathrm{GHz})$. Moreover, the properties of the GA, applied in this case, are the following: initial population set consists of twenty (20) elements. The best cost functions are used to generate the novel population. The probability of crossover is $100 \%$ from the best selected and the single point crossover technique is used with mutation probability equal to $0.1 \%$.

Compared to conventional methods, designers optimize all filter parameters with adding, in most cases, extra components in the cost of bulk and size [13-15].

\section{RESULTS AND DISCUSSION}

\section{A. Simulation}

The simulated reflexion coefficient $\left|S_{11}\right|$ of the wide-band antenna with and without non-conventional DGS filter is shown in Fig. 2. It is clearly noticeable that the DGS has effectively rejected the WiMAX band centred at $3.7 \mathrm{GHz}$. This result highlights the capability of the GAO to overcome optimization challenges.

To furthermore validate the proposed approach, the study of surface current distribution is carried out. The simulated current distribution is illustrated in Fig. 3, for resonant frequencies of $3.7 \mathrm{GHz}$ (rejected frequency) and $6 \mathrm{GHz}$. One can clearly observe, from this figure, the effect of incorporating the nonconventional DGS filter where currents are concentrated around the filter part as seen in Fig. 3(a) corresponding to the rejected frequency $(3.7 \mathrm{GHz})$. In this case, the antenna does not radiate and the currents are trapped by the filter. When comparing to Fig. 3(b), we can conclude that the filter does not disturb the frequency $6 \mathrm{GHz}$, which is radiated by the antenna.

For more emphasis, the gain variation is shown in Fig. 4. It's obvious that the filtering effect is achieved at the rejected frequency of $3.7 \mathrm{GHz}$ where the gain decreases drastically from

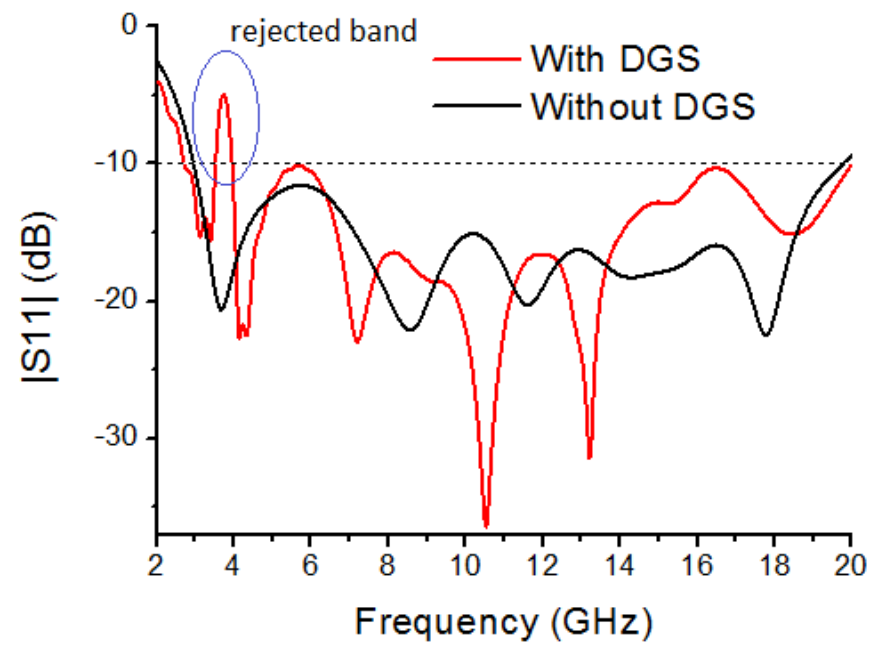

Fig. 2: Simulated $\left|S_{11}\right|$ with and without DGS filter.
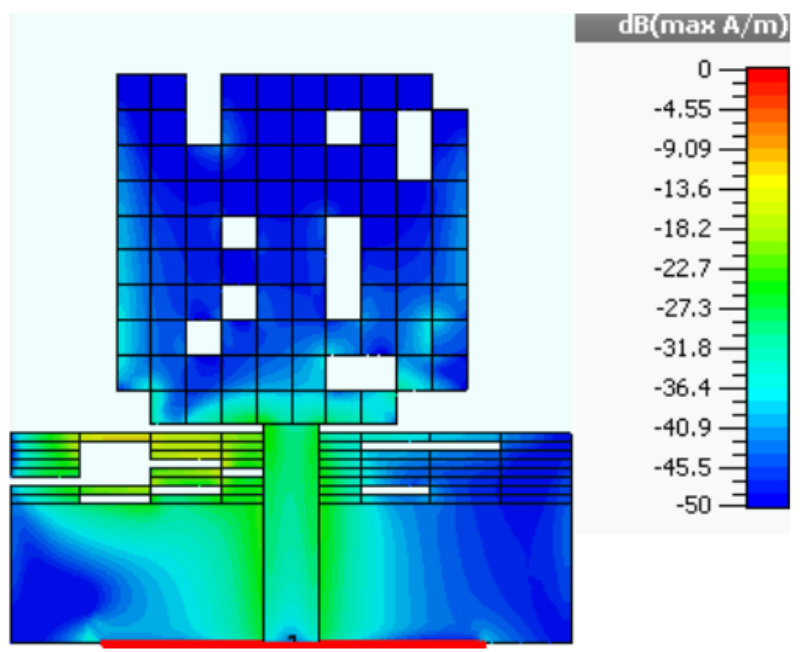

(a)

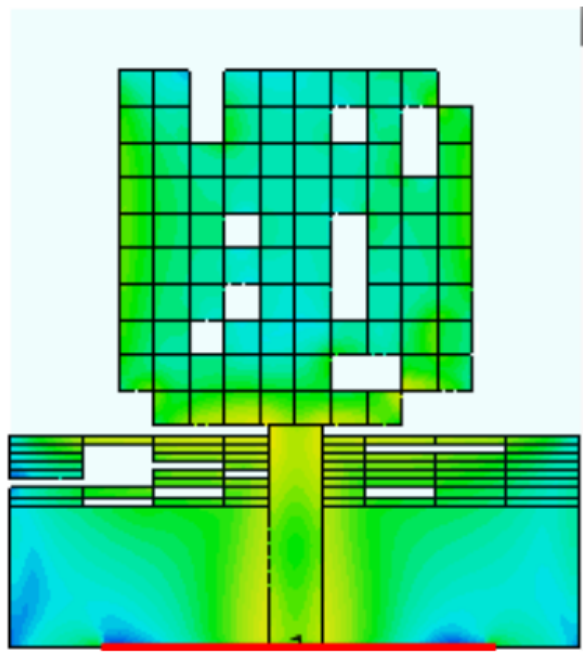

dB(max A/m)

(b)

Fig. 3: Surface current distributions at (a) $3.7 \mathrm{GHz}$ (b) $6 \mathrm{GHz}$.

$4.4 \mathrm{~dB}$ to less than $-14 \mathrm{~dB}$.

Beside, the radiation pattern of the proposed design is investigated. Simulated radiation patterns before and after DGS filter optimization are shown in Fig. 5 and Fig. 6 respectively, at different frequencies $3 \mathrm{GHz}, 5 \mathrm{GHz}$ and $13 \mathrm{GHz}$. It is seen that the 


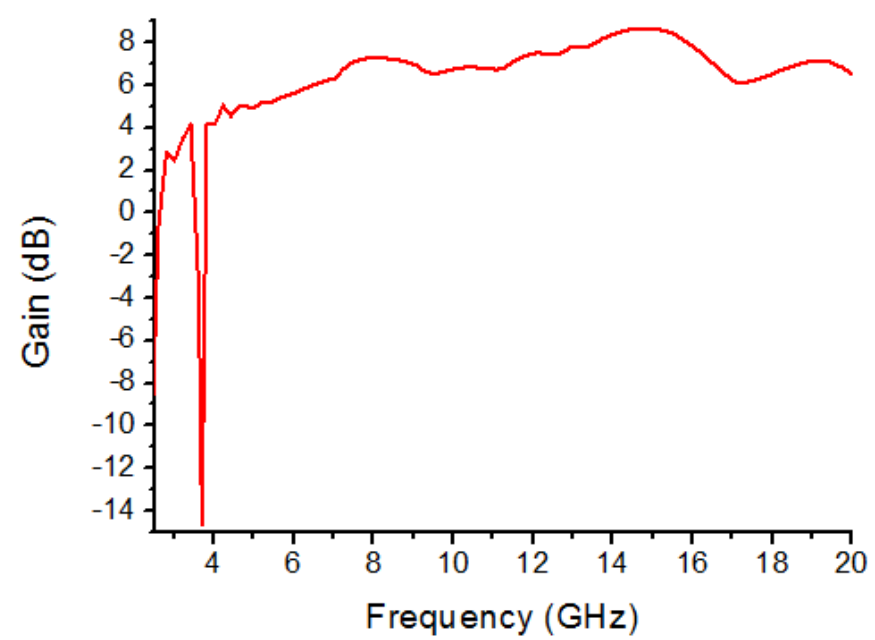

Fig. 4: Gain of the antenna with proposed DGS filter.

pattern is omnidirectional in H-plane $\left(P h i=0^{\circ}\right)$ and takes the eight shape in the E-plane $\left(P h i=90^{\circ}\right)$ which is similar to that of a simple monopole in the lower band ( 3 and $5 \mathrm{GHz}$ ). In the upper band $(13 \mathrm{GHz})$, the pattern is somehow distorted, this is may due to the excitation of higher modes. Moreover, it is observed that radiation patterns before and after DGS filter optimization are quasi-similar. This demonstrates that the optimized filter did not affect the radiation.

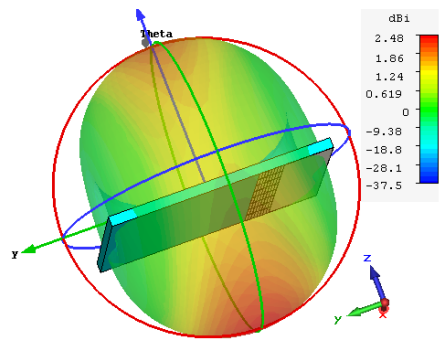

$\mathrm{F}=3 \mathrm{GHz}$

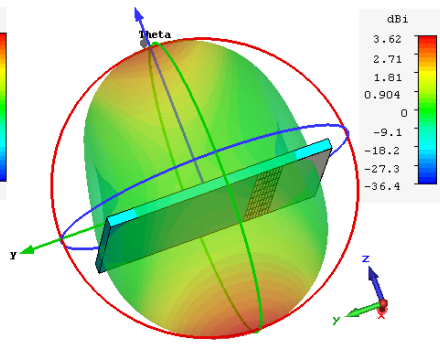

$\mathrm{F}=5 \mathrm{GHz}$

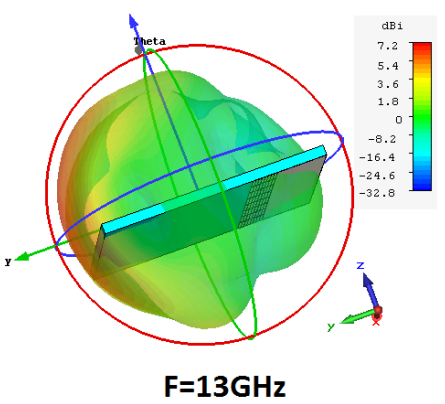

Fig. 5: Simulated 3D radiation pattern at $3 \mathrm{GHz}, 5 \mathrm{GHz}$ and $13 \mathrm{GHz}$, before DGS filter optimization.

\section{B. Measurement}

In order to validate experimentally the proposed approach, a prototype of the antenna is fabricated and measured as seen in Fig. 7.

Fig. 8 depicts the simulated and measured reflexion coefficient $S_{11}$-Parameter of the proposed antenna with non-conventional DGS filter. It is well noticed that the WiMAX band centered at $3.7 \mathrm{GHz}$ is effectively rejected. Moreover, simulation and measurement are in quite agreement with a small noticed discrepancy in high frequency (starting from $17 \mathrm{GHz}$ ) where measured
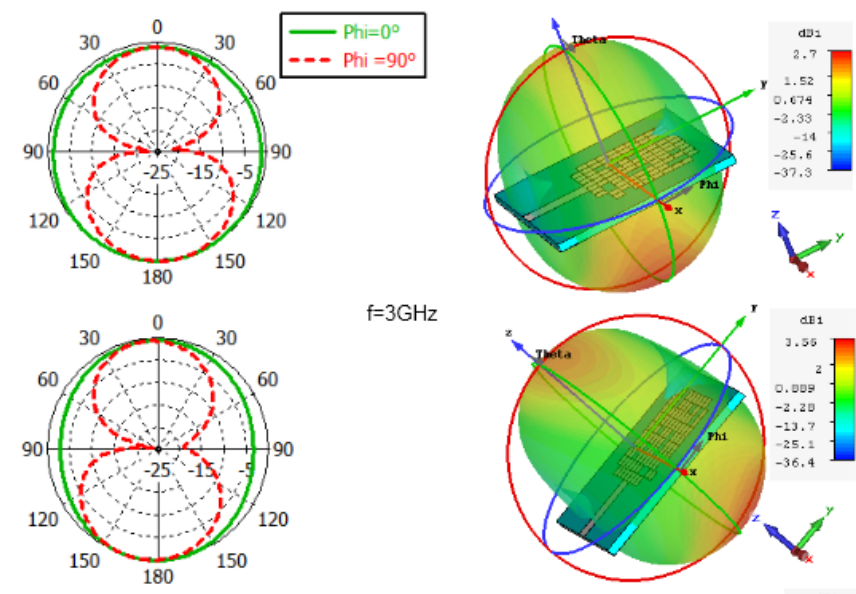

$f=3 \mathrm{GHz}$
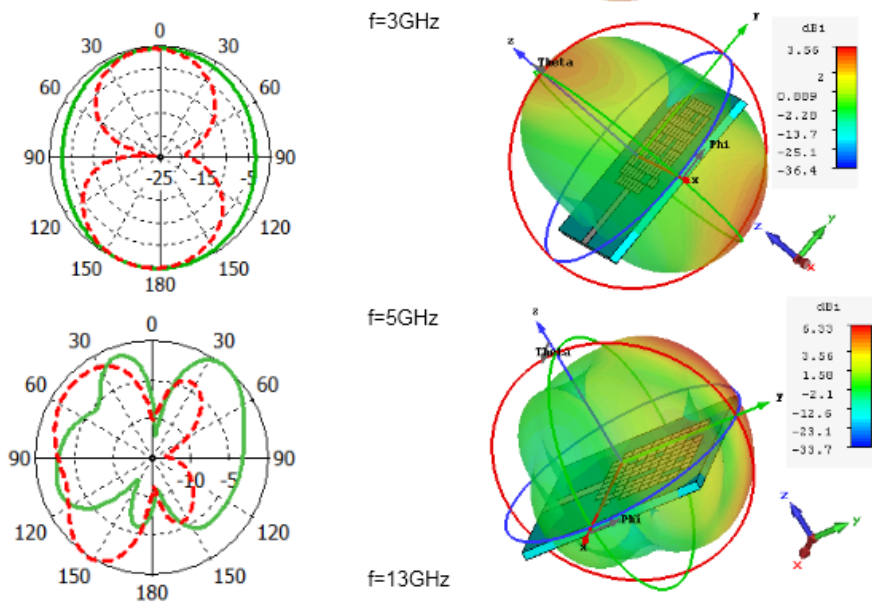

$\mathrm{f}=5 \mathrm{GHz}$

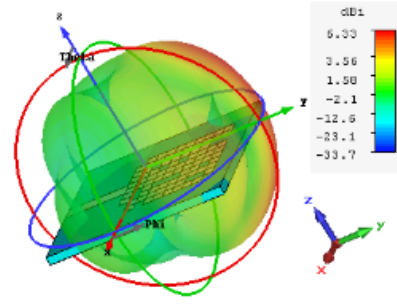

Fig. 6: Simulated 2D\&3D radiation pattern at $3 \mathrm{GHz}, 5 \mathrm{GHz}$ and $13 \mathrm{GHz}$ after DGS filter optimization.

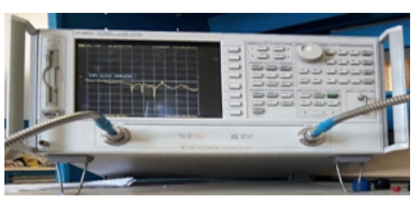

(a)

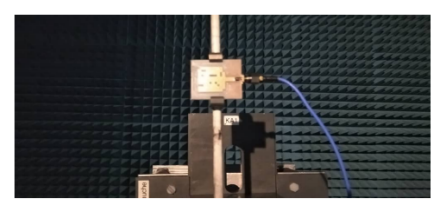

(b)
Fig. 7: $S_{11}$ and pattern measurement testbed (a) Network analyzer (b) Anechoic chamber.

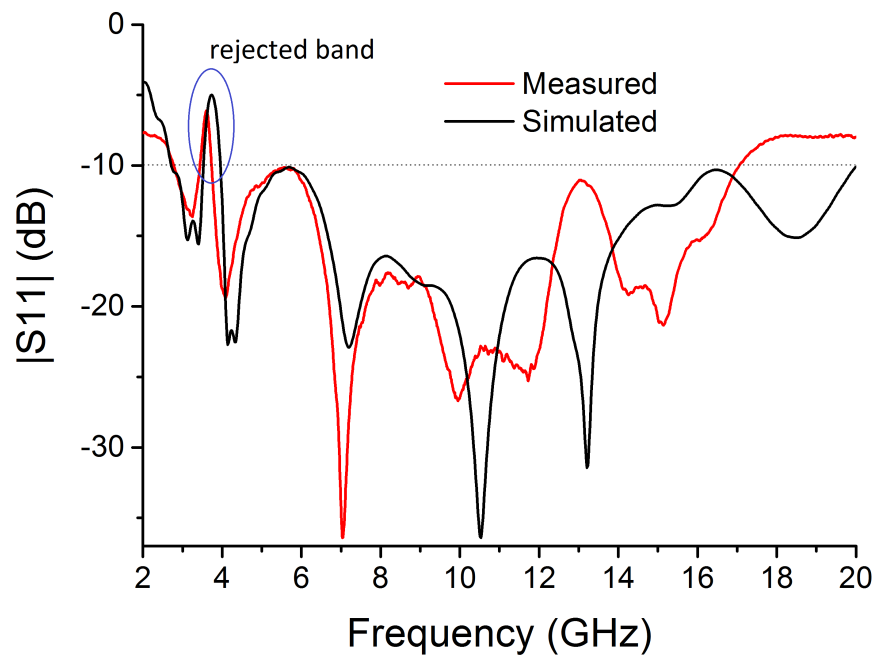

Fig. 8: Simulated and measured reflexion coefficient $S_{11^{-}}$ Parameter of the antenna with non-conventional DGS filter.

$S_{11}$ exceeds slightly $-10 \mathrm{~dB}$, contrary to simulation. This discrepancy may due to fabrication tolerances, variation in relative permittivity of the substrate in such high frequencies, measurements conditions ( $S_{11}$ measurements were carried out outdoor of anechoic chamber) and the use of SMA connector with maximum frequency of less than $18 \mathrm{GHz}$. Although this small discrepancy, it can be confirmed that the proposed approach is 


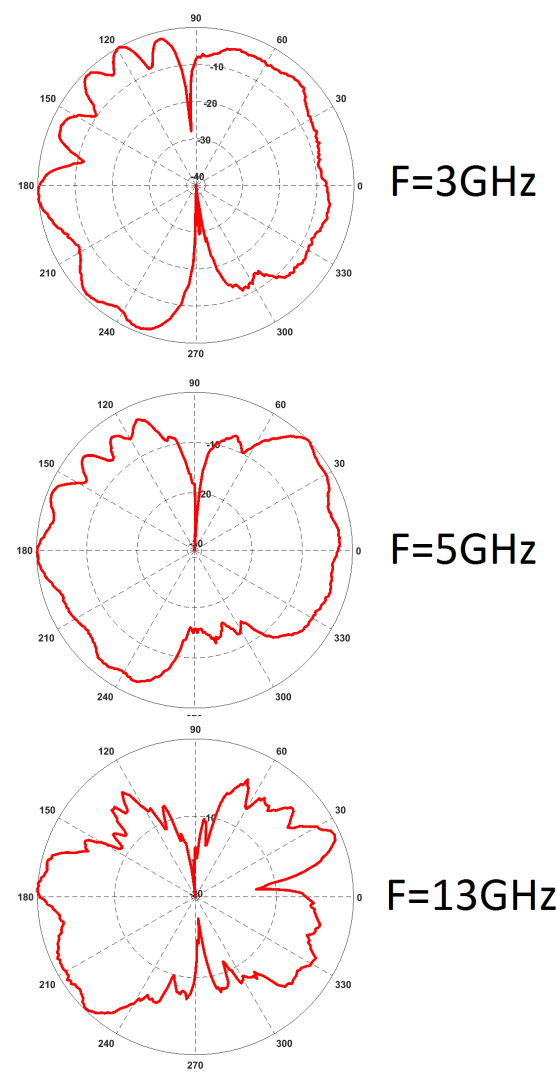

Fig. 9: Measured radiation pattern at $3 \mathrm{GHz}, 5 \mathrm{GHz}$ and $13 \mathrm{GHz}$ after DGS filter optimization.

practical and easily applicable. Further, Radiation pattern of the optimized antenna was measured in LEME Laboratory (Paris Nanterre University) anechoic chamber as depicted in Fig. 7(b). Obtained results at $3 \mathrm{GHz}, 5 \mathrm{GHz}$ and $13 \mathrm{GHz}$ are shown in Fig. 9. It is observed that patterns are almost similar to conventional monopole antenna as they are quasi-omnidirectional except for the higher frequency of $13 \mathrm{GHz}$, where distortions, due to higher modes, are observed. It can be then stated that the DGS filter did not affect the radiation of the proposed antenna.

\section{CONCLUSION}

In this paper, a new approach to optimize a non-conventional DGS filter based on GA for wide-band antenna is presented. The main advantage of this method is the ability for automatically providing DGS filter structures to cancel some undesired bands. Hence, the WiMAX band (taken as example) is successfully rejected by using the proposed approach. The GAO code is developed under VBS and implemented in CST Microwave software. Measurement and simulation results confirm the effectiveness of the proposed approach which is also practical and easily applicable.

The future perspectives of our present work are the optimization of reconfigurable DGS filter in order to reject several bands. Consequently, the proposed antenna will demonstrate advanced flexibility in term of frequency functionalities.

\section{ACKNOWLEDGEMENT}

Authors would like to thank sincerely Dr. Ratni Badreddine, Mr. Xavier Durocher and Dr. El-Korso Mohammed Nabil (Laboratoire Energétique, Mécanique, Electromagnétisme (LEME),
Université Paris Nanterre, France) for their kind assistance and support.

\section{REFERENCES}

[1] T. Abdurrahim, and M. Yerlikaya, "A compact reconfigurable ultra-wideband G-shaped printed antenna with band-notched characteristic," Microwave and Optical Technology Letters, 61.1, pp. 245-250, 2019. https://doi.org/10.1002/mop.31516

[2] R. Azim, M. T. Islam, and A. T. Mobashsher, "Dual Band-Notch UWB Antenna With Single Tri-Arm Resonator," IEEE Antennas and Wireless Propagation Letters 13, pp. 670-673, 2014. https://doi.org/10.1109/LAWP.2014.2314486

[3] L. C. Tsai, and W. J. Chen, "A UWB antenna with bandnotched filters using slottype split ring resonators," Microwave Opt. Technol. Lett., vol. 58, pp. 2595-2598, 2016. https://doi.org/10.1002/mop.30101

[4] F. Guichi, M. Challal and T. A. Denidni, "A Novel Dual BandNotch Ultra-Wideband Monopole Antenna using Parasitic Stubs and Slot," MOTL - Microw. and optic. Technol. Lett., vol. 60(7), pp. 1737-1744, Jul. 2018. https://doi.org/10.1002/mop.31231

[5] X.-K. Gao, H. M. Lee, and S.-P. Gao, "A Robust Parameter Design of Wide Band DGS Filter for Common-Mode Noise Mitigation in High-Speed Electronics," IEEE Trans. on Electromagn. Compat., 59(6), pp. 1735-1740, 2017. https://doi.org/10.1109/TEMC.2017.2710202

[6] K. Fertas, F. Ghanem, M. Challal, and R. Aksas "Design and Development of Compact Reconfigurable Tri-Stopband Bandstop Filter Using Hexagonal Metamaterial Cells for Wireless Applications" Progress In Electromagnetics Research M, Vol. 80, pp. 93-102, 2019. https://doi.org/10.2528/PIERM1810230.

[7] J. B. Jadhav and P. J. Deore, "A compact planar ultra-wideband bandpass filter with multiple resonant and defected ground structure," AEU-Intern. J. of Electron. and Commun., 81, pp. 31-36, 2017. https://doi.org/10.1109/APMC.2016.7931400

[8] K. Fertas, H. Kimouche, M. Challal, H. Aksas et al. "Design and optimization of a CPW-fed tri-band patch antenna using genetic algorithms," ACES- Applied Computational Electromagnetics Society Journal, vol. 30(7), 2015.

[9] S. Arianos, J. A., Quijano, G., Dassano, F. Vipiana et al. "Automated Design and Experimental Validation of a Reconfigurable, Board-Mounted Compact Antenna," IEEE Antennas and Wireless Propag. Lett. vol. 16, pp. 589-592, 2017. https://doi.org/10.1109/LAWP.2016.2591326

[10] K. Fertas, S. Tebache, F. Ghanem, S. Tedjini and R. Aksas, "Non-conventional Multiband Patch Antenna Design with Filtering Aspect Based on Genetic Algorithm," IETE Journal of Research. vol.66, n 6,pp. 815-822, 2020.https://doi.org/10.1080/03772063.2019.1634496.

[11] J. W. Jayasinghe, J. Anguera, D. N. Uduwawala and A. Andújar "A multipurpose genetically engineered microstrip patch antennas: Bandwidth, gain, and polarization," Microw. and Opt. Technol. Lett., vol. 59(4), pp. 941-949, 2017. https://doi.org/10.1002/mop.30439

[12] K. Fertas, H. Kimouche, M. Challal, et al., "Development of a Novel UWB Planar Antenna using a Genetic Algorithm," IEEE - 5th ICEE, Boumerdes, Algeria, pp. 29-31 October 2017. https://doi.org/10.1109/ICEE-B.2017.8192102

[13] X.-L. Liu, Y.-Z. Yin, and J.-H. Wang, "A compact dual bandnotched UWB antenna with meandering slot and C-shape strips," Microw. Opt.Technol. Lett., vol. 55, no. 11, pp. 2631-2636, 2013. https://doi.org/10.1002/mop.27896 
[14] X.-L. Liu, Y.-Z. Yin, P. A. Liu, J.-H. Wang, and B. Xu, “A CPWfed dual band-notched UWB antenna with a pair of bended dualL-shape parasitic branches," Prog. Electromagn. Res., vol. 136, pp. 623-634, 2013. https://doi.org/10.2528/PIER12122507

[15] C. Wang, Z.-H. Yand, B. Li, and P. Xu, "A dual band-notched UWB printed antenna with C-shaped and a U-shaped slot," Microw. Opt.Technol. Lett., vol. 54, no. 6, pp. 1450-1452, 2012. https://doi.org/10.1002/mop.26807

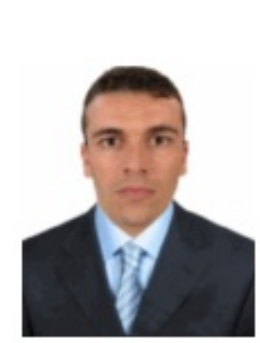

Khelil Fertas received the engineering degree in 2006 from University of M'sila, Algeria, and the MS degree in January 2014 from Ecole Militaire Polytechnique, Algiers, Algeria. In 2021, he received the PhD from Ecole Nationale Polytechnique (ENP), Algeria. His fields of interest include optimization, RF passive and active circuits and antennas.

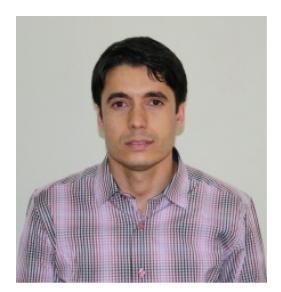

Soufiane Tebache received the Engineering degree from Polytechnic School, Algeria, in 2009, with honors (first class), and the Magister degree in Signals \& Communications from Biskra University, in 2013 with honors as well (first class). He defended recently his $\mathrm{PhD}$ thesis in telecommunications at Ecole Nationale Polytechnique (ENP), Algeria. His current research interests include: Antenna \& RF system- design, Microwaves, Electromagnetic field theory and Propagation, MIMO systems, Wireless communications, IoT and 5G.

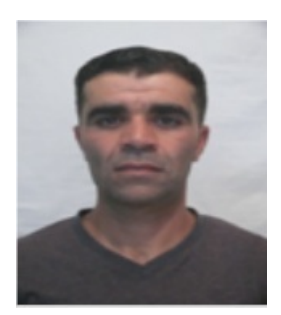

Fouad Fertas received the M.S. and Ph.D degrees from Boumerdes University, Algeria, respectively in 2016 and 2020. His fields of interest include Propagation and Antennas.

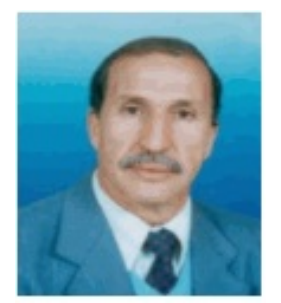

Rabia Aksas was born in 1950, Algeria. He received the MS and Doctorate degrees in electronics from Ecole Nationale Polytechnique, Algiers, Algeria, respectively in 1982 and 1995. Currently, he is a full Professor in the Electronics Department at Ecole Nationale Polytechnique. His research interests are in the areas of electromagnetic field theory, microwaves, propagation and antennas. 